Л. С. Семёнова

Белорусский государственный технологический университет

\title{
О СОВЕРШЕНСТВОВАНИИ СИСТЕМЫ МОНИТОРИНГА РИЭЛТЕРСКОЙ ДЕЯТЕЛЬНОСТИ В РЕСПУБЛИКЕ БЕЛАРУСЬ
}

Цель настоящей работы - проанализирвоать существующую систему мониторинга деятельности риэлтерских организаций в Республике Беларусь и предложить пути ее совершенствования. В работе рассмотрена система взаимодействия риэлтерских организаций с потребителями риэлтерских услуг и государственными органами, приведены показатели, по которым на сегодняшний день оценивается риэлтерская деятельность, выявлены недостатки в их содержании и порядке получения информации регулирующими органами.

В основе очень сложной системы лежит бумажный документооборот. Отсутствует четкая инструкция по предоставлению отчетности, а также отсутствует доступ к статистическим данным отрасли. Существующий порядок проведения мониторинга не позволяет оценить реальное положение дел в анализируемой отрасли ни регулирующим органам, ни потребителям риэлтерских услуг, ни самим риэлтерским организациям.

В статье приведено понятие риск-ориентированного подхода и высказаны предложения по его внедрению в мониторинг деятельности риэлтерских организаций. Разработан перспективный перечень показателей мониторинга, призванный сделать анализ деятельности более объективным, а саму деятельность более эффективной и прозрачной. Система включает в себя как абсолютные, так и относительные показатели, характеризующие качество и эффективность деятельности риэлтерских организаций.

Ключевые слова: риэлтерская деятельность, мониторинг, риск-ориентированный подход, критерии эффективности, критерии качества.

Для цитирования: Семёнова Л. С. О совершенствовании системы мониторинга риэлтерской деятельности в Республике Беларусь // Труды БГТУ. Сер. 5, Экономика и управление. 2021. № 1 (244). C. $146-150$.

\section{S. Semenova \\ Belarusian State Technological University \\ ABOUT THE IMPROVEMENT OF MONITORING OF REAL ESTATE ACTIVITY IN THE REPUBLIC OF BELARUS}

The purpose of this work is to analyze the existing system of monitoring of the real estate activity in the Republic of Belarus and suggest ways to improve it. The article considers the system of interaction of real estate organizations with consumers and government agencies, provides indicators of real estate activity assessment, which are used today, identifies shortcomings in their content and the procedure of obtaining information by regulatory agencies.

The basis of the very complex system is paper workflow. There is no clear instruction on reporting, and there is no access to industry statistics. The existing monitoring procedure does not allow assessing the real state of affairs in the analyzed industry for regulatory authorities, consumers of real estate services, real estate organizations.

The article describes the concept of a risk-oriented approach and makes proposals for its implementation in monitoring of real estate activity. A promising list of monitoring indicators has been developed, it designes to make the analysis more objective, and the real estate activities more effective and transparent. The system includes both absolute and relative quality and efficiency indicators of the real estate activity.

Key words: real estate activity, monitoring, risk-based monitoring, performance indicators, quality indicators.

For citation: Semenova L. S. About the improvement of monitoring of real estate activity in the Republic of Belarus. Proceeding of BSTU, issue 5, Economics and Management, 2021, no. 1 (244), pp. 146150 (In Russian).

Введение. В соответствии с положениями международного стандарта ISO 9001:2015 «Системы менеджмента качества - требования» мониторинг является неотъемлемой частью управления процессами оказания услуг и производства продукции. Одной из наиболее распространенных методологий 
управления процессами PDCA (цикл Деминга Plan - Do - Check - Act) предполагается регулярное проведение проверок и оценки результативности процессов на основе ключевых показателей эффективности, выявление и анализ отклонений от запланированных показателей, причин данных отклонений для последующей корректировки процесса. Проведение мониторинга позволяет определить узкие места процесса, точки роста, тем самым добиться повышения качества [1].

Оказание риэлтерских услуг является не просто коммерческой деятельностью по содействию в проведении сделок с недвижимым имуществом, но и социально-значимой деятельностью, поскольку недвижимое имущество - одно из самых дорогостоящих экономических благ, которыми владеют граждане, а также место их проживания и средство обеспечения достойного уровня жизни. Мониторингу такой деятельности должно уделяться пристальное внимание со стороны регулирующих государственных органов.

Основной целью статьи является анализ действующего порядка осуществления мониторинга деятельности риэлтерских организаций и формирование предложений по повышению его эффективности.

Основная часть. Существующая система мониторинга риэлтерской деятельности в Республике Беларусь. Оказание риэлтерских услуг является достаточно сложным процессом. Риэлтерская организация взаимодействует с потребителями риэлтерских услуг, множеством государственных ведомств, запрашивая информацию, необходимую для подготовки и проведения сделок, государственными регулирующими органами (рисунок).

Риэлтерская деятельность в Республике Беларусь представлена более чем 140 частными и шестью государственными риэлтерскими организациями. Данный вид деятельности является лицензируемым, а регулирующим государственным органом выступает Министерство юстиции. Помимо Министерства юстиции деятельность риэлтерских организаций, как и других коммерческих организаций, интересна Министерству по налогам и сборам, Министерству экономики, Министерству антимонопольного регулирования и торговли и др.

Порядок осуществления деятельности риэлтерских организаций определяется множеством нормативных правовых актов, главным из которых является Указ Президента Республики Беларусь от 9 января 2006 г. № 15 «О риэлтерской деятельности в Республике Беларусь» (далее Указ). В соответствии с данным Указом основой взаимодействия потребителей с риэлтерскими организациями является договор на оказание риэлтерских услуг, составленный на бумажном носителе и зарегистрированный в книге регистрации договоров. В соответствии с этим же указом риэлтерская организация обязана препятствовать удостоверению и государственной регистрации сделки, которая может быть признана недействительной по основаниям, предусмотренным законодательством [2].

В соответствии с действующим законодательством для выполнения требований Указа в процессе подготовки и проведения сделок с недвижимым имуществом риэлтерские организации запрашивают информацию, содержащуюся в более чем 15 различных государственных информационных ресурсах (ГИР) (по оценкам профессиональных участников рынка, это более 150000 бумажных запросов в год).

Мониторинг же деятельности такой сложной системы проводится в первую очередь на основании прямых обращений потребителей, по факту совершения нарушений.

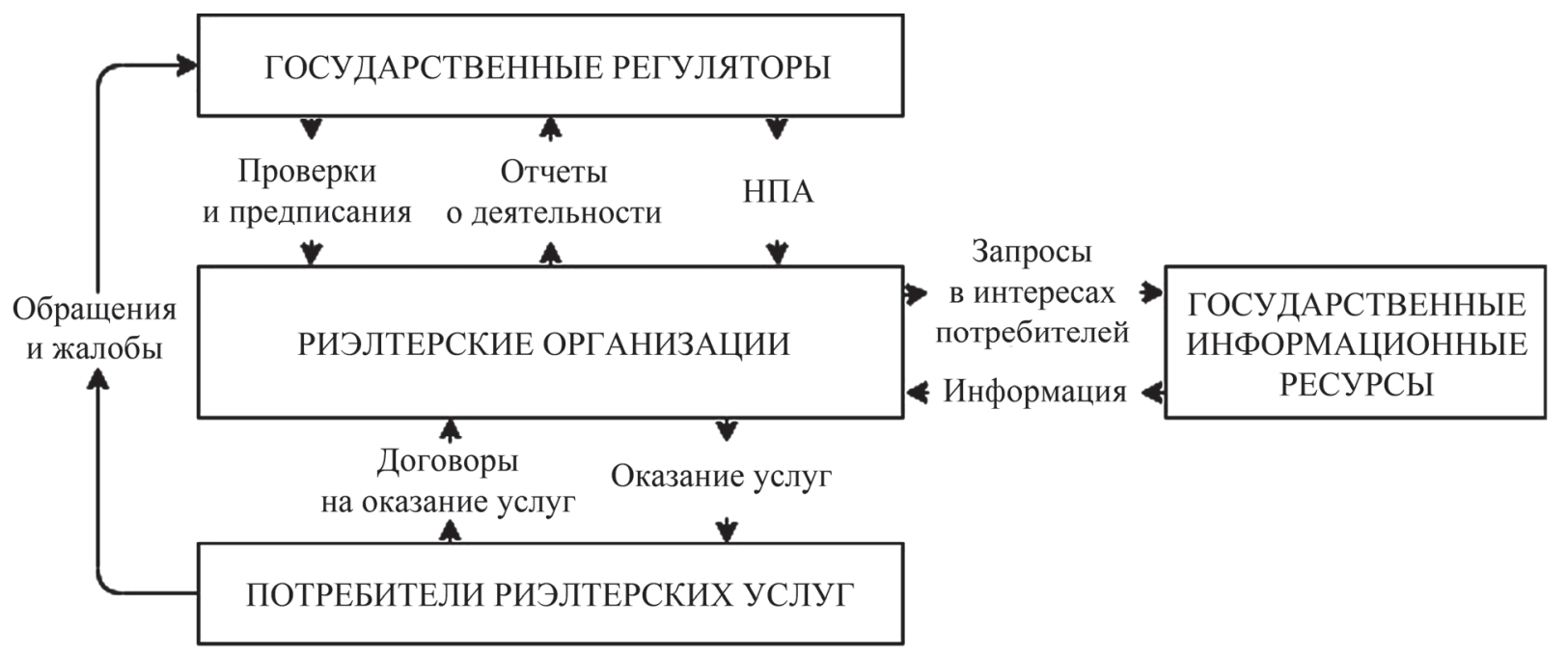

Схема взаимодействия риэлтерских организаций при оказании риэлтерских услуг (собственная разработка автора) 
Форма отчета утверждается ежегодно, представляет собой таблицу с наименованиями показателей. Инструкции к заполнению данного отчета регулирующим органом не предоставляется, а сам отчет передается регулятору на бумажном носителе, что делает обработку предоставленных данных крайне сложной. Основными данными, отраженными в отчете, являются следующие: о численности и движении персонала организации, о количестве заключенных, исполненных и расторгнутых договоров на оказание риэлтерских услуг, финансовые показатели (выручка, платежи в бюджет, финансовый результат), количестве опубликованных материалов в средствах массовой информации, количестве проверок регулирующих органов, объявленных предписаний и взысканий, актах о страховых случаях по обязательному страхованию ответственности и т. д.

Несмотря на такое количество информации, предоставляемой риэлтерскими организациями, в стране в прямом доступе отсутствует статистика о деятельности отрасли, в частности о количестве заключенных договоров на оказание риэлтерских услуг и, соответственно, доле сделок с недвижимым имуществом, совершенных при посредничестве риэлтерских организаций. Данный факт лишает потребителей риэлтерских услуг возможности выбора наиболее подходящей для себя риэлтерской организации и вынуждает использовать лишь информацию, представленную в СМИ и рекламных материалах организаций. Субъекты рынка в свою очередь не могут объективно оценить свое конкурентное положение и повлиять на отношение к ним потребителей. Обнаружение нарушения в деятельности одной риэлтерской организации бросает тень сразу на всех профессиональных участников рынка.

Анализ показателей отчетности позволяет говорить о недостаточности данных для мониторинга. В частности, не представляется возможным оценить, была ли проведена риэлтерской организацией проверка всех обстоятельств сделки, во все ли необходимые инстанции были сделаны запросы и нет ли риска признания в будущем сделки недействительной. По данным Национального кадастрового агентства, ежегодно около 160 сделок купли-продажи недвижимого имущества признается недействительными [3]. Среди сделок, проводимых при посредничестве риэлтерских организаций, такие случаи единичны, однако это не умаляет величину рисков и сложность проведения подобных сделок.

Существующая система мониторинга характеризуется следующими недостатками:

- непрозрачность деятельности организаций за счет бумажного документооборота и взаимодействия «человек-человек»;
- несистематизированное получение данных о деятельности организаций регулирующим органом;

- отсутствие единого источника статистической информации о деятельности риэлтерских организаций;

- мониторинг деятельности носит запаздывающий, а не предупреждающий характер;

- отсутствие инструментов контроля за получением и использованием персональных данных, получаемых при подготовке к проведению сделок с недвижимым имуществом;

- высокие трудозатраты на подготовку отчетности;

- регулирующие органы не владеют объективной информацией о рынке и не имеют инструментов прямого контроля всех видов деятельности риэлтерских организаций.

Предложения по совершенствованию системы мониторинга деятельности риэлтерских организаций. Основой для совершенствования системы мониторинга и, как следствие, развития риэлтерской деятельности в Беларуси должны стать следующие факторы: цифровизация риэлтерской деятельности за счет внедрения системы электронной регистрации договоров на оказание риэлтерских услуг, интегрированной со средой электронного правительства для получения информации из государственных информационных ресурсов, и автоматизация мониторинга.

На сегодняшний день по заказу Союза компаний по реинжинирингу риэлтерской деятельности Национальным центром электронных услуг разработан и подготовлен к эксплуатации информационный ресурс «Электронный реестр договоров на оказание риэлтерских услуг». Союзом ведется работа по передаче ресурса государственным органам. Для внедрения его в работу риэлтерских организаций необходимо согласие Министерства юстиции.

На первом этапе планируется получение с помощью реестра данных из государственных информационных ресурсов Национального кадастрового агентства, Министерства внутренних дел и Министерства по налогам и сборам.

При внедрении ресурса любым заинтересованным регулирующим органом в любой момент времени может быть получена исчерпывающая информация о заключенных договорах на оказание риэлтерских услуг и работе, проделанной в целях исполнения данных договоров.

Внедрение полноченного риск-ориентированного подхода к мониторингу. Успешный опыт внедрения риск-ориентиро-ванного подхода к мониторингу уже есть в Российской Федерации. В соответствии с Федеральным законом от 26 декабря 2008 г. № 294-Ф3 (ред. от 08 декабря 2020) 
«О защите прав юридических лиц и индивидуальных предпринимателей при осуществлении государственного контроля (надзора) и муниципального контроля» риск-ориентированный подход представляет собой метод организации и осуществления государственного контроля (надзора), при котором в предусмотренных законом случаях выбор интенсивности (формы, продолжительности, периодичности) проведения мероприятий по контролю, мероприятий по профилактике нарушения обязательных требований определяется отнесением деятельности юридического лица, индивидуального предпринимателя и (или) используемых ими при осуществлении такой деятельности производственных объектов к определенной категории риска либо определенному классу (категории) опасности [4].

В Беларуси разработан перечень критериев, на основании которых должны проводиться выборочные проверки деятельности риэлтерских организаций [5]. Среди них невыполнение вынесенных регулирующим органом предписаний или рекомендаций, количество обоснованных жалоб, факт нарушения законодательства о лицензировании, требований других нормативных правовых актов, регулирующих риэлтерскую деятельность, привлечение должностных лиц организации к административной ответственности, факт непредоставления в срок или предоставления недостоверной информации в отчетности. Данные критерии не позволяют полноценно оценить качество деятельности организаций и степень риска для проведения проверки по тем же причинам, которые описаны выше.

Проведение мониторинга должно осуществляться в режиме реального времени по мере запросов со стороны регулирующих органов. Система должна автоматически на основе заранее заданных критериев определять субъектов с высокой степенью риска для перевода их в число субъектов, деятельность которых требует проверки, и минимизации негативных последствий.

Представляется, что в основу методики мониторинга должен быть положен «метод анализа иерархий» (Analytic Hierarchy Process - AHP). Meтодика должна включать в себя следующие этапы:

- определение количественно измеряемых ключевых индикаторов KPI фактически достигнутых результатов эффективности деятельности объектов оценки (факторов) и множества субфакторов, позволяющих осуществлять измерение каждого КРI;

- принятие правила присвоения каждому фактору и субфактору численного значения по принятой шкале оценок;

- определение роли (веса) каждого фактора и каждого из субфакторов в интегральной оценке качества деятельности организаций;
- принятие правила определения интегральной оценки уровня качества деятельности объектов оценки;

- разработка правила выработки решения о переводе организаций, подлежащих мониторингу и надзору, в ту или иную зону риска.

Изменение и дополнение системы показателей, анализируемых в прочессе мониторинга.

Для проведения риск-ориентированного мониторинга риэлтерской деятельности предлагается использовать факторы качества и эффективности осуществления деятельности.

К факторам качества осуществления деятельности относятся:

- количество судебных споров по признанию сделок, проводимых при посредничестве риэлтерских организаций, недействительными с признаннием вины риэлтерских организаций;

- количество обоснованных жалоб о нарушении риэлтерскими организациями законодательства в области лицензирования;

- количество обоснованных жалоб о нарушении риэлтерскими организациями других нормативных правовых актов, регулирующих риэлтерскую деятельность;

- доля расторгнутых договоров на оказание риэлтерских услуг в организации за анализируемый период (отношение числа расторгнутых к общему числу заключенных договоров на оказание риэлтерских услуг в организации за анализируемый период);

- доля неисполненных договоров на оказание риэлтерских услуг в организации за анализируемый период (отношение числа неисполненных к общему числу заключенных договоров на оказание риэлтерских услуг в организации за анализируемый период);

- среднее количество запросов в ГИР системы электронного правительства для надлежащего исполнения договоров (количество запросов в ГИР, приходящееся на один заключенный договор на оказание риэлтерских услуг), показатель рассчитывается отдельно по каждому виду риэлтерских услуг.

К факторам эффективности осуществления деятельности относятся:

- средняя выручка, приходящаяся на одного специалиста по риэлтерской деятельности в организации за анализируемый период (отношение суммы выручки риэлтерской организации за анализируемый период к среднесписочной численности специалистов по риэлтерской деятельности);

- отношение средней выручки, приходящейся на одного специалиста по риэлтерской деятельности в организации за анализируемый период, к организациям-лидерам по региону (сравнивается средняя выручка в анализируемой организации и в организациях-лидерах по данному показателю по региону (г. Минск, областные центры, районные центры, другие города). 
Заключение. Риэлтерская деятельность является довольно сложной системой взаимодействия риэлтерских организаций, потребителей риэлтерских услуг и государственных органов. Нормативные правовые акты, регулирующие риэлтерскую деятельность, в большинстве своем были разработаны и приняты более 10 лет назад и на сегодняшний день морально устарели. Существующая система мониторинга риэлтерской деятельности не позволяет предупреждать нарушения со стороны риэлтерских организаций и не повышает прозрачность деятельности, в основе которой лежит бумажный документооборот и взаимодействие «человек-человек». Рекомендуется переход к электронной системе регистрации договоров на оказание риэлтерских услуг, интегрированной с системой электронного правительства, развитие риск-ориентированного подхода к мониторингу и изменение перечня критериев мониторинга. Использование предложенных абсолютных и относительных показателей при проведении мониторинга позволит объективно оценивать деятельность риэлтерских организаций для предотвращения нарушений, проведения проверок, а также поможет создать здоровую конкурентную среду на рынке риэлтерских услуг, сделает риэлтерскую деятельность более эффективной и прозрачной.

\section{Список литературы}

1. Системы менеджмента качества - Требования: ISO 9001:2015. URL: https://pqm-online.com/ assets/files/pubs/translations/std/iso-9001-2015-(rus).pdf (дата обращения: 11.02.2021).

2. О риэлтерской деятельности в Республике Беларусь: Указ Президента Респ. Беларусь, 9 янв. 2006 г., № 15 // Нац. реестр правовых актов Респ. Беларусь. 2006. № 15. 1/7130.

3. Национальное кадастровое агентство. Развитие системы государственной регистрации. Статистика. Аналитика. URL: http://nca.by/rus/reg/razvitie-sistemy-gos-registracii/god_otchet_2018/ (дата обращения: 11.02.2021).

4. О защите прав юридических лиц и индивидуальных предпринимателей при осуществлении государственного контроля (надзора) и муниципального контроля: Федер. закон, 26 дек. 2008 г., № 294-Ф3 (ред. от 08 дек. 2020 г.). URL: http://www.consultant.ru/document/cons_doc_LAW_83079/ (дата обращения: 11.02.2021).

5. О критериях оценки степени риска для отбора проверяемых субъектов при проведении выборочной проверки: приказ Министерства юстиции Респ. Беларусь, 20 февр. 2018 г., № 25 // Министерство юстиции Республики Беларусь. URL: https://minjust.gov.by/ (дата обращения: 11.02.2021).

\section{References}

1. ISO 9001:2015. Sistema menedzhmenta kachestva - Trebovaniya [Quality management systems Requirements]. Available at: https://pqm-online.com/assets/files/pubs/translations/std/iso-9001-2015-(rus).pdf (accessed 11.02.2021).

2. About the real estate activity in The Republic of Belarus: Decree of the President of the Republic of Belarus, 09.01.2006, no. 15. Natsional'nyy reestr pravovykh aktov Respubliki Belarus' [National register of legal acts Republic of Belarus], 2006, no. 15. 1/7130.

3. Natsional'noye kadastrovoye agentstvo. Razvitiye sistemy gosudarstvennoy registratsii. Statistika. Analitika [National Cadastral Agency. Development of the state registration system. Statistics. Analytics]. Available at: http://nca.by/rus/reg/razvitie-sistemy-gos-registracii/god_otchet_2018/(accessed 11.02.2021).

4. O zashchite prav yuridicheskikh lits $i$ individual'nykh predprinimateley pri osushchestvlenii gosudarstvennogo kontrolya (nadzora) i munitsipal'nogo kontrolya: Federal'nyy zakon, 26.12.2008, № 294-FZ (red. 08.12.2020). [About the protection of the rights of legal entities and individual entrepreneurs in the exercise of state control (supervision) and municipal control: The Federal Law, 26.12.2008, № 294-FL (ed. 08.12.2020)]. Available at: http://www.consultant.ru/document/cons_doc_LAW_83079/(accessed 11.02.2021).

5. About the indicators for assessing the degree of risk for the selection of inspected subjects during the selective inspection. Ministerstvo yustitsii Respubliki Belarus', 20.02.2018 [Order of Justice Ministry of the Republic of Belarus, 20.02.2018]. Available at: https://minjust.gov.by/ (accessed 11.02.2021).

\section{Информация об авторе}

Семёнова Людмила Сергеевна - аспирант кафедры организации производства и экономики недвижимости. Белорусский государственный технологический университет $(220006$, г. Минск, ул. Свердлова, 13a, Республика Беларусь). E-mail: semyonova.mila.s@gmail.com

\section{Information about the author}

Semenova Lyudmila Sergeevna - PhD student, Department of Production Organization and Real Estate Economics. Belarusian State Technological University (13a, Sverdlova str., 220006, Minsk, Republic of Belarus). E-mail: semyonova.mila.s@gmail.com 